\title{
In Vivo Result
}

National Cancer Institute

\section{Source}

National Cancer Institute. In Vivo Result. NCI Thesaurus. Code C41100.

An Invivo Result captures the results of anti-tumor drug screening. 